\title{
Increased Fracture Risk After Bariatric Surgery: a Case-Controlled Study with a Long-Term Follow-Up
}

\author{
Omar Suhail Alsaed ${ }^{1} \cdot$ Abdul-Wahab Al-Allaf $^{1} \cdot$ Isra Elgenaied $^{2} \cdot$ Rawand Abdelnaser Jebril $^{1} \cdot$ Sreethish Sasi $^{1}$. \\ Ashraf Omer Ahmed ${ }^{1}$. Rabab Boussarsar ${ }^{2}$. Mohamed Izham Mohamed Ibrahim ${ }^{3}$. Ibrahim Abdulmomen ${ }^{1}$. \\ Wahiba Elhag ${ }^{2}$. Samar A. Al Razaq Alemadi ${ }^{1}$
}

Received: 3 April 2021 / Revised: 2 August 2021 / Accepted: 4 August 2021

(c) The Author(s) 2021

\begin{abstract}
Purpose Bariatric surgeries are common procedures due to the high prevalence of obesity. This study aimed to investigate whether bariatric surgery increases fracture risk.

Material and Methods It was a case-controlled study. Patients who underwent bariatric surgery during 2011 and 2012 were matched for age ( \pm 5 years) and gender to patients on medical weight management during the same period with a ratio of $1: 2$. The index date was defined as the date of bariatric surgery for both groups. The subject's electronic medical records were reviewed retrospectively to identify fractures documented by radiology during January 2020.

Results Randomly selected 403 cases were matched to 806 controls with a median age of 36.0 years (IQR 14.0) and 37.0 years (IQR 14.0), respectively. Seventy per cent of the cohort were females. Eighty per cent received sleeve gastrectomy, and the remaining (17\%) underwent gastric bypass. The mean duration of follow-up was 8.6 years. The fracture rate was higher in the surgical group as compared to the controls (9.4\% vs 3.5\%) with a crude odds ratio of 2.71 (95\% CI 1.69-4.36). The median duration for time to fracture was 4.17 years for the surgical group and 6.09 years for controls ( $\mathrm{p}$-value $=0.097$ ). The most common site of fractures was feet, followed by hands. Apart from a few wrist fractures, there was no typical osteoporotic sites fracture.

Conclusion Subjects who underwent bariatric procedures had more non-typical osteoporotic site fractures affecting mainly feet and hands, and fractures tend to occur earlier as compared to controls.
\end{abstract}

Keywords Bariatric surgery $\cdot$ Fracture $\cdot$ Osteoporosis $\cdot$ Obesity $\cdot$ Malabsorption

\section{Introduction}

Bariatric surgeries are common procedures with an estimate of $>340,000$ operations done in 2011 worldwide [1], and in 2019, around 256,000 bariatric procedures in the USA alone [2]. It is one of the most effective options for achieving significant and durable weight loss. It has short- and long-term complications despite the restricted

Key Points:

- Bariatric surgery increases the risk of fractures.

- The increased risk of fractures will be detected after a longterm follow-up.

- Bariatric surgery long-term follow-up in the Middle East.

Abdul-Wahab Al-Allaf

awallaf@gmail.com; Aalallaf1@hamad.qa

Extended author information available on the last page of the article indications which were updated in 2019 by the American Association of Clinical Endocrinologists, the Obesity Society, and the American Society for Metabolic and Bariatric Surgery (ASMBS) [3].

Bone mineral content loss has been investigated in many studies. A systematic review and meta-analysis revealed that patients who underwent bariatric surgery had significant bone mineral density (BMD) deterioration $[4$, 5] Most of the bariatric procedures included in these studies were malabsorptive surgeries. BMD loss and fracture post-bariatric procedures have never been estimated in Middle East countries.

The impact of different bariatric procedures on fracture risk was investigated in a few studies; two studies were conducted in the UK population and 4 in North America and Canada. These studies were retrospective, and they differed with the type of bariatric procedures 
and duration of follow up (Appendix Table 6). The results from these studies were contradictory. The two studies from the UK did not show a statistically significant increment in fracture risk [6,7]. While in a large, matched cohort study from Canada, fracture risk increased significantly by 1.85 -folds in the surgical group [8] and 1.21 (95\% CI 1.02-1.43) from a similar study from Taiwan [9]. A meta-analysis of 6 studies published in 2018 showed an increase in fracture risk in all and non-vertebral sites, especially in the upper limbs (RR 1.42, 95\% CI 1.08-1.87, and RR 1.68, 95\% CI 1.15-2.45). Fracture risk tended to increase in 2 years after surgery but became similar to that of the non-surgical group from years 2 to 5 . Notably, only two studies with a mean follow-up of 4.8 years were included in this meta-analysis. The authors of this meta-analysis had suggested having more studies with longer follow-up the duration to investigate the change in fracture risk following bariatric surgery [10]. Another point that urges us to conduct this study results from previous studies was mainly from European and North American populations which cannot be generalized for all populations as it is well known that the mentioned populations have higher fragility fracture rates compared to Asian and African populations [11].

BMD loss and fracture risk post-bariatric procedures have never been estimated in our region or compared with those for the rest of the world. We are expecting that the fracture rate is higher than global figures due to the high prevalence of vitamin D insufficiency in our region, which is $80-90 \%$ $[12,13]$. However, our study has not designed to answer this question.

The main objective of this study is to investigate whether bariatric surgical intervention increases the risk of fracture. Our study has the advantage of a long follow-up period, and it reflects the situation in the Middle East as most of the previous studies were in the Western.

\section{Materials and Methods}

Subjects who underwent bariatric surgery during 2011 and 2012 were screened for the eligibility criteria until the calculated sample size reached. Patients and controls were selected randomly from this pool during this period. Selected cases were matched with controls for gender and age ( \pm 5 years) in a ratio of $1: 2$. Controls were selected from the patients' pool who received non-surgical weight reduction management and followed in the same bariatric clinics. The index date was defined as the date of the bariatric surgery. As our controls do not fitful the criteria to be eligible for surgical intervention, it is difficult to match the two groups with regard to the BMI. Both groups were followed retrospectively from the index date until January 2020 for fracture events as documented by the radiologist.

Data collected from the bariatric and metabolic surgery centre (BMSC) database, which is the principal tertiary centre in Qatar, provides medical and surgical weight management. Bariatric surgical intervention is conducted under ASMBS indications [3]. Cases and controls were randomly selected from those with obesity who underwent medical or surgical weight reduction management during 2011 and 2012 and were included. We took every other patient or control from our electronic lists pool.

Exclusion criteria: patients who are known to have osteoporosis, malignancies, chronic kidney disease, or those who underwent previous gastric banding or gastric balloon, and subjects who did not have clinic visits for more than 2 years from the index date were excluded.

We collected data for all the possible cofounders including exposure to corticosteroid exposure ( $>2$ prescriptions of systemic corticosteroid after the index date), protein pump inhibitors, and antiepileptics, medical conditions including autoimmune diseases such as systemic lupus erythematosus, rheumatoid arthritis and spondyloarthropathy, primary hyperparathyroidism, inflammatory bowel disease and history of fracture before the index date. Multivariate logistic regression analysis to calculate the adjusted risk ratio was developed.

Our electronic medical records (EMR) are connected to the EMR of the primary healthcare system. Each person in Qatar has a unique healthcare number that carries all medical records throughout his life. For data validation, we did a phone survey for 100 subjects to compare their fracture history with their EMR for fracture events and those were compatible.

\section{Statistical Analysis}

Data from the CERNER ${ }^{\circledR}$ system (patient health record) was input into an Excel sheet. Statistical analyses were done using SPSS 26 for Windows. Data were described using frequency (percentage), mean $\pm S D$, or median (IQR). Kolmogorov-Smirnov test was used to determine the data normality. Chi-square test or Fisher exact test, independent $t$ test or Mann Whitney $U$, and one-way analysis of variance (ANOVA) or Kruskal-Wallis test were used for inferential analysis. The risk of fracture was determined using univariate and multivariate logistic regression models. Hosmer and Lemeshow test used to test the overall fit of a model to the observed data. The Cox model for survival data using hazard analysis was applied to assess risk between the interventions. All $\mathrm{p}$ values presented were two-tailed and an alpha value of 0.05 . 


\section{Results}

\section{Subject Characteristics}

Randomly selected 573 potential subjects who received bariatric surgery between 01.01.2011 and 31.12.2012 were screened for the inclusion and exclusion criteria. A total of 170 subjects were excluded as per our exclusion criteria. The remaining 403 cases were matched to 806 controls with a mean (SD) duration of follow-up for both groups was $8.07 \mp 0.023$ years $(95 \%$ CI $8.03-8.12)$. Both patients and controls were followed for the same period. The subject's characteristics for both groups are summarized in Table 1. Median age was 36.0 years (IQR 14.0) for surgical group vs 37.0 years (IQR 14.0) for the control group $(p=0.13)$. No significant differences were found for the gender and age group at $>40$ years. As expected the surgical group had a significantly higher baseline median BMI (IQR) 46.93 (7.21) as compared with controls 35.49
(11.9). However, we also found that the surgical group had a higher pre-index date fracture rate $(5 \%$ vs $1 \%)$, proton pump inhibitor uses (41.2\% vs $11.9 \%)$, primary hyperparathyroidism $(0.7 \%$ vs $0.0 \%)$, and inflammatory bowel disease $(0.5 \%$ vs $0.0 \%)$ as compared with controls, respectively. Sleeve gastrectomy was performed in $83 \%$ and gastric bypass in $17 \%$.

\section{Fracture Risk Results (Tables 2 and 3)}

Fracture events were significantly higher in the surgical group (38 or $9.4 \%$ ) as compared with the controls $(28$ or $3.5 \%)$ with an odds ratio of 2.71 (95\% CI 1.69-4.36). Numerically, there were more fractures in females $(p=0.299)$. Fractures occur at a statistically younger age in the surgical group as compared with controls (median IQR age at the time of the fracture was $36.0 \mp 14$ years in the surgical group and $37 \mp 14$ in controls, $\mathrm{p}=0.013$ ). Although the baseline BMI was
Table 1 Baseline demographic and clinical data characteristics of both study groups

Table 2 Demographic and clinical data characteristics of the fractured patients in both study groups

\begin{tabular}{|c|c|c|c|}
\hline & \multicolumn{2}{|l|}{ Study group } & \multirow[t]{2}{*}{ p-value } \\
\hline & Case $(n=403)$ & $\begin{array}{l}\text { Control } \\
(\mathrm{n}=806)\end{array}$ & \\
\hline Females $(\%)$ & $284(70.5)$ & $586(72.6)$ & 0.434 \\
\hline Median (IQR) age, years & $36.0(14.0)$ & $37.0(14.0)$ & $0.013 *$ \\
\hline Age group $>40, \mathrm{n}(\%)$ & $126(31.3)$ & $282(34.9)$ & 0.202 \\
\hline Median (IQR) BMI at baseline, $\mathrm{Kg} / \mathrm{m}^{2}$ & $46.93(7.21)$ & 35.49 (11.90) & $<0.0001 *$ \\
\hline Fractures before index date, n (\%) & $20(5.0)$ & $8(1.0)$ & $<0.0001$ \\
\hline Systemic corticosteroid, n (\%) & $6(1.5)$ & 37 (4.6) & 0.006 \\
\hline Proton pump inhibitor, $\mathbf{n}(\%)$ & $166(41.2)$ & 96 (11.9) & $<0.0001$ \\
\hline Antiepileptics, n (\%) & $7(1.7)$ & $9(1.1)$ & 0.372 \\
\hline Spondyloarthropathy, n (\%) & $1(0.2)$ & $0(0)$ & 0.333 \\
\hline Primary hyperparathyroidism, n (\%) & $3(0.7)$ & $\mathbf{0}(\mathbf{0})$ & $\mathbf{0 . 0 3 7}$ \\
\hline Rheumatoid arthritis, n (\%) & $0(0)$ & $1(0.1)$ & 0.480 \\
\hline Inflammatory bowel disease, $n(\%)$ & $2(0.5)$ & $\mathbf{0}(\mathbf{0})$ & 0.045 \\
\hline Systemic lupus erythematosus, $\mathrm{n}(\%)$ & $0(0)$ & $2(0.2)$ & 0.317 \\
\hline
\end{tabular}

Chi-square test or Fisher's exact test was carried out if $25 \%$ of the cells have expected count less than 5 . *Mann Whitney test

\begin{tabular}{lllc}
\hline & $\begin{array}{l}\text { Cases } \\
(\mathbf{n = 3 8})\end{array}$ & Control $(\mathbf{n = 2 8})$ & p value \\
\hline Gender n (\%) & & & \\
$\quad$ Female & $27(71.1)$ & $23(82.1)$ & 0.299 \\
Male & $11(28.9)$ & $5(17.9)$ & \\
Median (IQR) age at the time of fracture, years & $36.0(14)$ & $37.0(14)$ & 0.013 \\
Median (IQR) BMI at baseline, Kg/m ${ }^{2}$ & $46.9(7.21)$ & $35.4(11.11)$ & $<0.0001$ \\
Median (IQR) BMI at time of fracture, $\mathrm{Kg} / \mathrm{m}^{2}$ & $36.17(6.94)$ & $35.98(11.36)$ & 0.763 \\
Time to the event, median (IQR) & $4.17(3.65)$ & $6.09(2.84)$ & 0.097 \\
\hline
\end{tabular}


Table 3 Anatomical distribution of fracture events for both groups with odd ratio and $95 \%$ CI

\begin{tabular}{llllll}
\hline Item & Case $(\mathrm{n}=403)$ & Control $(\mathrm{n}=806)$ & p value & Odd ratio & Odd ratio 95\% CI \\
\hline Total fracture events N (\%) & $\mathbf{3 8}(\mathbf{9 . 4})$ & $\mathbf{2 8}(\mathbf{3 . 5})$ & $<\mathbf{0 . 0 0 0 1}$ & $\mathbf{2 . 7 1}$ & $\mathbf{( 1 . 6 9 - 4 . 3 6 )}$ \\
Upper limb fractures N (\%) & $11(2.7)$ & $13(1.6)$ & 0.188 & 1.71 & $0.76-3.86$ \\
Humerus & $1(0.2)$ & $2(0.2)$ & 0.704 & 1.00 & $0.09-11.07$ \\
Radio/ulnar & $3(0.7)$ & $6(0.7)$ & 0.623 & 1.00 & $0.24-4.02$ \\
Hand & $7(1.7)$ & $5(0.6)$ & 0.065 & 2.83 & $0.89-8.99$ \\
Lower limb fractures N (\%) & $25(6.2)$ & $14(1.7)$ & $<0.001$ & 3.74 & $1.92-7.28$ \\
Femur & $0(0)$ & $0(0)$ & - & -- & - \\
Tibia & $3(0.7)$ & $0(0)$ & 0.037 & -- & - \\
Fibula & $6(1.5)$ & $2(0.2)$ & 0.019 & 6.08 & $1.22-30.27$ \\
Foot & $16(4.0)$ & $12(1.6)$ & 0.011 & 2.52 & $1.20-5.30$ \\
Spine fractures N $(\%)$ & $2(0.5)$ & $1(1.0)$ & 0.259 & 4.02 & $0.36-44.46$ \\
\hline
\end{tabular}

significantly higher in the surgical group, the BMI at the time of the fractures was not significantly different between the two groups (median IQR BMI at the time of fracture was 36.17 (6.94) years in the surgical vs 35.98 (11.36) years in the controls, $p=0.763)$. This means that fracture tends to occur earlier in the surgical group than in the controls (median 4.17 years with IQR 3.65 vs 6.09 with IQR 2.84 and $p=0.097$ ). There was no statistically significant difference in the site of the fractures in the two groups.

The time for the highest hazard risk ratio for fracture post-bariatric surgery in comparison with the non-surgical group is around year 6 . The cumulative hazard risk between study groups is equal to 7.3 years. Figure 1 illustrates the cumulative hazard risk of fracture between study groups over the study period.

\section{Adjusted Fracture Risk}

In the simple logistic regression (testing for single variable separately), we found that the age group at a cutoff point of 40 years old $(p=0.038)$, the surgical group $(\mathrm{p}<0.0001)$ if the patient is taking proton pump inhibitor $(\mathrm{p}=0.001)$ and if the patient is taking an antiepileptic medication $(\mathrm{p}<0.0001)$, baseline $\mathrm{BMI}$ level $\geq 35$ $(p=0.001)$ and baseline BMI level $\geq 40(p=0.001)$ were found significantly associated with the cases of fracture (Table 4). Patients who were more than 40 years old have a lower odds $(\mathrm{OR}=0.592)$ of association (i.e. 1 patient with the age of more than 40 years old for every 1.7 patients with the age of equal or less than 40 years old). Patients who went through the surgery has almost 3 times more likely to experience a fracture. Among patients who took proton pump inhibitor and antiepileptic medications
Fig. 1 The surgical group (red) developed their fractures much earlier than controls (blue) with the largest gap in cumulative hazard was at 6 years

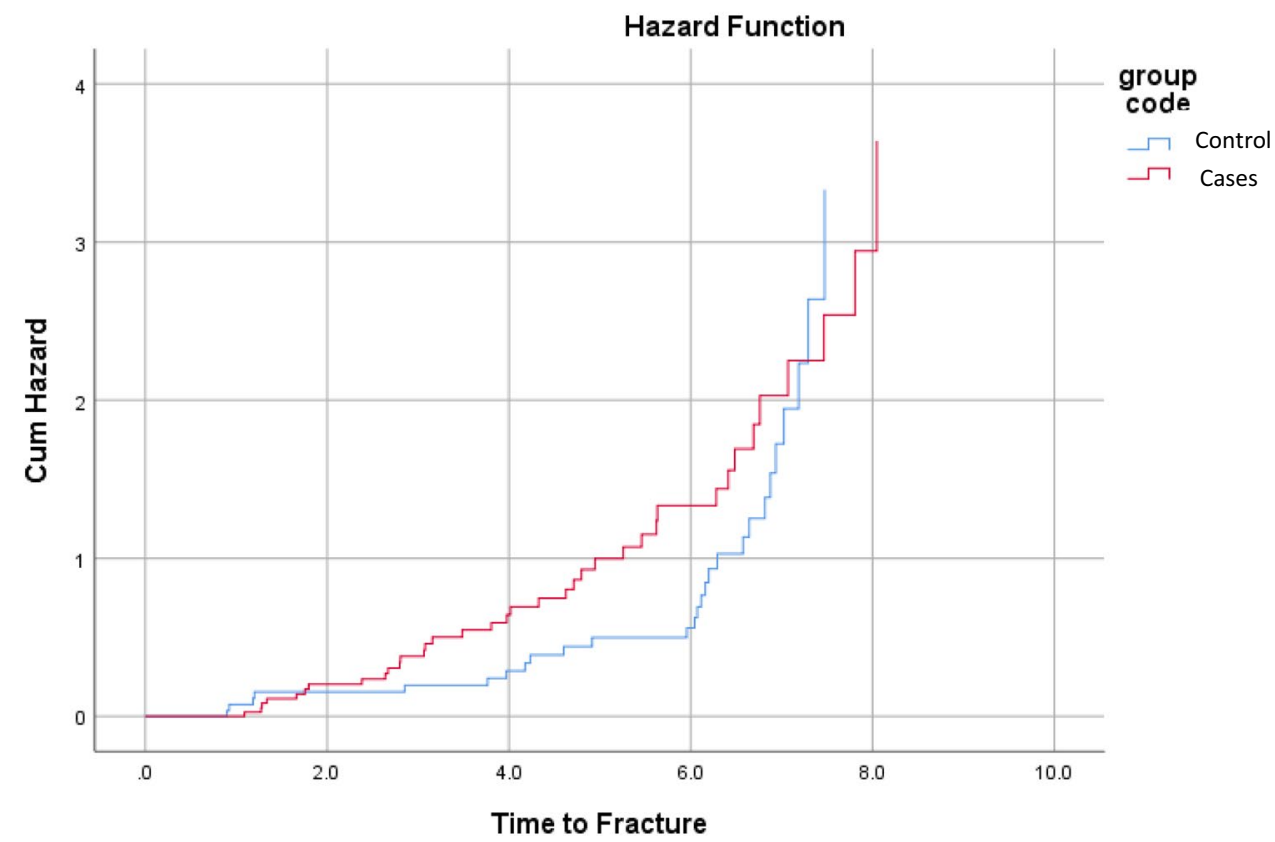


Table 4 Association of demographic and clinical data based on fractures incidence in both groups

\begin{tabular}{|c|c|c|c|c|}
\hline \multirow{2}{*}{ Confounders } & \multicolumn{2}{|c|}{ Fracture p-value } & \multirow[t]{2}{*}{ OR } & \multirow[t]{2}{*}{$95 \% \mathrm{CI}$} \\
\hline & Yes $(\%)$ & & & \\
\hline Female & $50(75.8)$ & 0.473 & 0.810 & $0.455-1.443$ \\
\hline Male & $16(24.2)$ & 0.473 & 0.810 & $0.455-1.443$ \\
\hline Age group $>40$ & $30(45.5)$ & 0.038 & 0.592 & $0.359-0.976$ \\
\hline Surgical group & $38(57.6)$ & $<0.0001$ & 2.896 & $1.750-4.793$ \\
\hline Systemic corticosteroid & $3(4.5)$ & 0.654 & 1.314 & $0.396-4.365$ \\
\hline Proton pump inhibitor & $237(20.7)$ & 0.001 & 2.334 & $1.391-3.915$ \\
\hline Spondyloarthropathy & $1(0.1)$ & 1.000 & 0.945 & $0.933-0.958$ \\
\hline Antiepileptic agent & $5(7.6)$ & $<0.0001$ & 8.443 & $2.844-25.062$ \\
\hline Systemic lupus erythematosus & $2(0.2)$ & 1.000 & 0.945 & $0.933-0.958$ \\
\hline Rheumatoid arthritis & $1(0.1)$ & 1.000 & 0.945 & $0.933-0.958$ \\
\hline Inflammatory bowel disease & $2(0.2)$ & 1.000 & 0.945 & $0.933-0.958$ \\
\hline Primary hyperparathyroidism & $3(0.3)$ & 1.000 & 0.945 & $0.933-0.958$ \\
\hline Fractures before surgery & $3(4.5)$ & 0.268 & 2.131 & $0.627-7.250$ \\
\hline Baseline $\mathrm{BMI} \geq 30$ & $63(100)$ & 0.997 & 0.000 & $0.000-\mathrm{na}$ \\
\hline Baseline $\mathrm{BMI} \geq 35$ & $56(88.9)$ & 0.001 & 0.274 & $0.124-0.608$ \\
\hline Baseline $\mathrm{BMI} \geq 40$ & $42(66.7)$ & 0.001 & 0.409 & $0.239-0.699$ \\
\hline
\end{tabular}

were around 2 times and 8 times more likely, respectively, to experience a fracture. Further, patients with BMI level of $\geq 35$ have a lower odds $(\mathrm{OR}=0.274)$ of association (i.e. 1 patient with the BMI level of $\geq 35$ for every approximately 4 patients with the BMI level of less than 35 ). In addition, patients with a BMI level of $\geq 40$ have a lower odds $(\mathrm{OR}=0.409)$ of association (i.e. 1 patient with a BMI level of $\geq 40$ for every approximately 2.5 patients with a BMI level of less than 40).

The significant variables in the simple logistic regression model are then brought into the multiple regression model, which is the real-life scenario, and confounders were taken into consideration. The results are shown in Table 5 .

It was indicated that patient's age above 40, surgical intervention group, and use of antiepileptic are significant predictors and risk factors associated with fractures. Patients who are in the bariatric surgery group have around 2 times more likely to have a fracture if compared to the controls. Patients whose age is above 40 have almost 2 times most likely to have a fracture compared to those below 40 years old. The findings also indicated that patients who are taking antiepileptic agents have around 7 times more likely to have a fracture, but PPI is not a risk factor for fracture.

\section{Discussion}

Firstly, we would like to point to the fact that our study had the highest period for post-bariatric surgical follow up of 8.6 years among the other published studies. In this single-centre case-control study, the risk of fracture in patients with obesity who underwent bariatric surgical intervention, mainly sleeve gastrectomy, was significantly higher at 2.7-folds comparing with age
Table 5 Multivariate logistic regression significant predictors and risk factors for fractures

\begin{tabular}{llllllll}
\hline Predictors & B & SE & Wald & df & p-value & Odds ratio & $95 \%$ CI \\
\hline Study group & .764 & .335 & 5.192 & 1 & .023 & 2.147 & $1.113-4.143$ \\
Age above 40 & .612 & .270 & 5.140 & 1 & .023 & 1.844 & $1.086-3.131$ \\
PPI & .426 & .293 & 2.111 & 1 & .146 & 1.530 & $0.862-2.717$ \\
AEP & 1.975 & .575 & 11.796 & 1 & .001 & 7.206 & $2.335-22.242$ \\
Baseline BMI $\geq 35$ & -.718 & .482 & 2.222 & 1 & .136 & .488 & $0.190-1.254$ \\
Baseline BMI $\geq 40$ & -.016 & .357 & .002 & 1 & .965 & .984 & $0.489-1.983$ \\
\hline
\end{tabular}

$B$ unstandardized regression weight, $S E$ standard error, Wald test test to determine significant predictor, $d f$ degree of freedom, $\operatorname{Sig}$ p value, $\operatorname{Exp}(B)$ odds ratio 
and gender-matched patients with obesity managed with weight reduction therapy. Nevertheless, the vast majority of the fractures were not typical for osteoporotic fragility fracture in both groups. These data pointed to negative sequelae of bariatric procedures on bone health in the long term which needs to be addressed. Post-bariatric surgery data gave no consistent results, but more data is pointing towards increasing the risk of fractures [6-9, 14-16]. These studies differed with the type of bariatric procedures and duration of follow-up (Appendix Table 6 summarized these studies).

As compared to previous studies, our study revealed the highest fracture risk in our surgical group with an OR of 2.71. We think this could be because our surgical intervention group had more history of previous fractures with proton pump and antiepileptics use as compared to controls. However, this could be counteracted by the fact that controls are more likely to be on steroids.

Two UK retrospective studies in 2012 and 2015 did not show a statistically significant increment in fracture risk $[6,7]$, and we think this could be due to the relatively short follow-up period of 3 years. Lu et al. (2015), from Taiwan, revealed a significantly increased risk of fractures at only 1.2-folds and a slightly longer mean follow-up duration of 4.8 years as compared to the above UK studies. The sub-analysis of this study revealed that the relative risk of fracture is significantly more for the malabsorptive procedure (HR: 1.47, 95\% CI 1.01-2.15) and not for the restrictive procedures (HR 1.17, 95\% CI 0.97-1.41). However, the study was not powered to show the difference between malabsorptive and restrictive procedures [9]

Rousseau et al. (2016) conducted the largest ever study in this area with 12, 676 patients in the bariatric surgery group and a matched 38, 028 obese patients who undergone a nonsurgical intervention and 12, 6760 non-obese patients. Fracture risk increased significantly by 1.8 -folds in the surgical group vs 1.13 in the obese non-surgical group in comparison with non-obese subjects [8]. In this study, the mean followup duration was only 4.4 years (Appendix Table 6).

We think the longer the duration for the follow-up, the more likely will be the increased risk for the fracture, and this has been demonstrated very well in our study and from the above discussion.

Whether fracture risk differs by the type of bariatric procedure was investigated by Yu et al. (2017), the conclusion was that Roux-en-Y gastric bypass was associated with a $43 \%$ (HR1.43, 95\% CI 1.13-1.81) increment in risk of nonvertebral fracture compared with adjustable gastric banding [15]. A meta-analysis ran by Zhang et al. (2018) showed a significant increase in non-vertebral fracture risk with RR
1.42. Sub-group analysis showed mixed surgical procedures (mixture of restrictive and malabsorptive procedure) compared with restrictive surgical procedure trended to have a higher fracture risk, but this finding was not statistically significant (RR 1.54, 95\% CI 0.96-2.46) [10]. Our strength for the study came from the fact that we have a reasonable number of the patient as calculated by sample size and the long duration of the follow-up (8.6 years). It also came from the Middle East where there is a paucity of data and where the population differs from the Western populations ( $\mathrm{R} 1$ and $\mathrm{R} 2$ ).

\section{The Limitations of our Study}

The surgical group was not BMI matched to the control group, which is understandable. This is important as it is well known that the higher the BMI, the more the fracture risk [8, 17-19]. In our study, the median BMI at the time of fracture was comparable between the surgical and control groups (36.17 vs 35.98). We also found that our surgical group is more likely to have previous fractures and be on proton pump inhibitors and antiepileptics as compared to controls, and that on contrary, controls are more likely to be on steroids which could affect our results. Smoking, alcohol consumption data, and other comorbidities that can affect bone health were missing in the majority of our patients, which we think could be important cofounders for fracture risk. Sub-clinical vertebral fractures were not included in the outcome, which could underestimate the fracture rate. Most of the fractures in our cohort are not a typical osteoporotic site for fracture; however, these results are pointing to negative sequelae on bone health in general, particularly in the first 4-yearspost-bariatric intervention. This highlights the importance of adherence to post-bariatric procedure recommendations like vitamins, minerals, and proteins supplements and to consider some intervention to counteract such risk. Lastly, we recommend that any future study in this respect should be prospective with consideration of the possible confounders and long enough to answer these important questions.

\section{Conclusion}

Our study was the first study that delineates fracture risk postbariatric procedure in the Middle Eastern population. The mean duration of follow-up is the longest as compared with previous studies and hence the highest risk for fracture. We also founded the possible confounders, which should be considered in any future study in this field.

Suitable intervention is needed to ameliorate the high risk in the surgical intervention group. 


\section{Appendix}

*Reference was estimated community fracture rate.

Table 6 Summarize studies that investigated fracture risk post-bariatric procedures

\begin{tabular}{|c|c|c|c|c|c|}
\hline Author, year & $\begin{array}{l}\text { Methods/matching } \\
\text { criteria }\end{array}$ & Sample size & Procedure & Follow up duration & Fracture risk \\
\hline $\begin{array}{l}\text { Lalmohamed, UK } 2012 \\
\text { [7] }\end{array}$ & $\begin{array}{l}\text { Retrospective case- } \\
\text { controlled study (age, } \\
\text { sex, BMI, practice, } \\
\text { year) }\end{array}$ & $\begin{array}{l}\text { Matching ratio 1:6 } \\
\text { Cases }(2079) \\
\text { Control }(10442)\end{array}$ & $\begin{array}{l}60 \% \text { adjustable gastric } \\
\text { banding } \\
29 \% \text { gastric bypass }\end{array}$ & Mean 2.2 & $\begin{array}{l}\text { RR: } 0.89 \\
95 \% \text { CI }(0.60-1.33)\end{array}$ \\
\hline $\begin{array}{l}\text { Nakamura, USA } 2014 \\
{[14]}\end{array}$ & $\begin{array}{l}\text { Retrospective observa- } \\
\text { tional study }\end{array}$ & 258 & $94 \%$ gastric bypass & Mean 8.9 & $\begin{array}{l}\text { *RR: } 2.3 \\
95 \% \text { CI } 1.8-2.8\end{array}$ \\
\hline $\begin{array}{l}\text { Lu, } \\
\text { Taiwan } 2015 \text { [9] }\end{array}$ & $\begin{array}{l}\text { Retrospective case- } \\
\text { controlled study } \\
\text { (age, sex, Charlson } \\
\text { comorbidity index, } \\
\text { diabetes, hyperten- } \\
\text { sion, hyperlipidemia) }\end{array}$ & $\begin{array}{l}\text { Cases (2064) } \\
\text { Control (5027) }\end{array}$ & $\begin{array}{l}86 \% \text { restrictive proce- } \\
\text { dure } \\
14 \% \text { malabsorptive } \\
\text { procedure }\end{array}$ & Mean 4.8 & $\begin{array}{l}\text { RR: } 1.21 \\
95 \% \text { CI } 1.02-1.43\end{array}$ \\
\hline $\begin{array}{l}\text { Douglas, } \\
\text { UK } 2015 \text { [6] }\end{array}$ & $\begin{array}{l}\text { Retrospective case- } \\
\text { controlled study } \\
\text { (age, sex, general } \\
\text { practice, and calendar } \\
\text { period) }\end{array}$ & $\begin{array}{l}\text { Match ratio: 1:1 } \\
\text { Case (3882) } \\
\text { Control (3882) }\end{array}$ & $\begin{array}{l}62.9 \% \text { restrictive pro- } \\
\text { cedure } \\
36.6 \% \text { malabsorptive } \\
\text { procedure }\end{array}$ & Mean 3.4 & $\begin{array}{l}\text { HR } 1.28 \\
95 \% \text { CI } 0.81-2.02\end{array}$ \\
\hline $\begin{array}{l}\text { Rousseau, Canada } 2016 \\
\text { [8] }\end{array}$ & $\begin{array}{l}\text { Retrospective nested } \\
\text { case-control study }\end{array}$ & $\begin{array}{l}\text { Cases }(12,676) \\
\text { Obese control }(38,028) \\
\text { Non-obese control } \\
\quad(126,760)\end{array}$ & $\begin{array}{l}27.4 \% \text { Sleeve gastrec- } \\
\text { tomy } \\
41.7 \% \text { gastric band } \\
9.3 \% \text { Gastric bypass } \\
21.3 \% \text { Biliopancreatic } \\
\text { diversion }\end{array}$ & Mean 4.4 & $\begin{array}{l}\text { RR: } 1.85 \\
95 \% \text { CI } 1.68-2.04\end{array}$ \\
\hline $\begin{array}{l}\text { Yu, E, } \\
\text { USA } 2017 \text { [15] }\end{array}$ & $\begin{array}{l}\text { Retrospective case- } \\
\text { controlled study (pro- } \\
\text { pensity score-matched } \\
\text { cohort) }\end{array}$ & $\begin{array}{l}\text { Matching 1:1 } \\
\text { Cases: gastric bypass } \\
\text { (7516) } \\
\text { Control: gastric band- } \\
\text { ing ( } 7516)\end{array}$ & & Mean 2.3 & $\begin{array}{l}\text { HR: } 1.43 \\
95 \% \text { CI } 1.13-1.81\end{array}$ \\
\hline $\begin{array}{l}\text { Fashandi, USA } 2018 \\
\text { [16] }\end{array}$ & $\begin{array}{l}\text { Retrospective case- } \\
\text { controlled study }\end{array}$ & $\begin{array}{l}\text { Matching 1:1 } \\
\text { Cases (1940) } \\
\text { Control (1940) }\end{array}$ & $\begin{array}{l}79.4 \% \text { Gastric bypass } \\
11.2 \% \text { Gastric banding } \\
7.8 \% \text { Sleeve gastrec- } \\
\text { tomy }\end{array}$ & Mean 7.6 & $\mathrm{p}$ value $<0.000$ \\
\hline
\end{tabular}

Acknowledgements We acknowledge all the consultant on our department re their support.

Author Contribution All authors contributed to the manuscript.

Funding Open access funding provided by the Qatar National Library.

\section{Declarations}

Ethical Approval This study had approval from the medical research centre of HMC under protocol number 01-18-042. Waiver consent was used to extract data from the subject's medical records.

Informed Consent A recorded verbal consent was obtained from the hundred subjects who were called for data validation.
Conflict of Interest All the authors declare no competing interests.

Open Access This article is licensed under a Creative Commons Attribution 4.0 International License, which permits use, sharing, adaptation, distribution and reproduction in any medium or format, as long as you give appropriate credit to the original author(s) and the source, provide a link to the Creative Commons licence, and indicate if changes were made. The images or other third party material in this article are included in the article's Creative Commons licence, unless indicated otherwise in a credit line to the material. If material is not included in the article's Creative Commons licence and your intended use is not permitted by statutory regulation or exceeds the permitted use, you will need to obtain permission directly from the copyright holder. To view a copy of this licence, visit http://creativecommons.org/licenses/by/4.0/. 


\section{References}

1. Buchwald H, Oien DM. Metabolic/bariatric surgery worldwide 2011. Obes Surg. 2013;23(4):427-36.

2. (ASMBS) ASfMaBS. Estimate of Bariatric surgery numbers. 2011-2019 [Jun,15 2021]; Available from: https://asmbs.org/ resources/estimate-of-bariatric-surgery-numbers

3. Mechanick JI, Apovian C, Brethauer S, Garvey WT, Joffe AM, Kim J, et al. Clinical practice guidelines for the perioperative nutrition, metabolic, and nonsurgical support of patients undergoing bariatric procedures - 2019 Update: Cosponsored by American Association of Clinical Endocrinologists/American College of Endocrinology, the Obesity Society, American Society for Metabolic \& Bariatric Surgery, Obesity Medicine Association, and American Society of Anesthesiologists - Executive Summary. Endocr Pract. 2019;25(12):1346-59.

4. Rodriguez-Carmona Y, Lopez-Alavez FJ, Gonzalez-Garay AG, Solis-Galicia C, Melendez G, Serralde-Zuniga AE. Bone mineral density after bariatric surgery. A systematic review Int J Surg. 2014;12(9):976-82.

5. Liu C, Wu D, Zhang JF, Xu D, Xu WF, Chen Y, et al. Changes in bone metabolism in morbidly obese patients after bariatric surgery: a meta-analysis. Obes Surg. 2016 Jan;26(1):91-7.

6. Douglas IJ, Bhaskaran K, Batterham RL, Smeeth L. Bariatric surgery in the United Kingdom: a cohort study of weight loss and clinical outcomes in routine clinical care. PLoS Med. 2015;12(12):e1001925.

7. Lalmohamed A, de Vries F, Bazelier MT, Cooper A, van Staa $\mathrm{TP}$, Cooper C, et al. Risk of fracture after bariatric surgery in the United Kingdom: population-based, retrospective cohort study. BMJ. 2012;345:e5085.

8. Rousseau C, Jean S, Gamache P, Lebel S, Mac-Way F, Biertho L, et al. Change in fracture risk and fracture pattern after bariatric surgery: a nested case-control study. BMJ. 2016;354:i3794.

9. Lu CW, Chang YK, Chang HH, Kuo CS, Huang CT, Hsu CC, et al. Fracture risk after bariatric surgery: a 12-year nationwide cohort study. Medicine (Baltimore). 2015;94(48):e2087.
10. Zhang Q, Chen Y, Li J, Chen D, Cheng Z, Xu S, et al. A metaanalysis of the effects of bariatric surgery on fracture risk. Obes Rev. 2018;19(5):728-36.

11 Cheng SY, Levy AR, Lefaivre KA, Guy P, Kuramoto L, Sobolev B. Geographic trends in incidence of hip fractures: a comprehensive literature review. Osteoporos Int. 2011;22(10):2575-86.

12 Badawi A, Arora P, Sadoun E, Al-Thani AA, Thani MH. Prevalence of vitamin d insufficiency in Qatar: a systematic review. J Public Health Res. 2012;1(3):229-35.

13 Zainel AAL, Qotba H, Al Nuaimi A, Syed M. Vitamin D status among adults (18-65 years old) attending primary healthcare centres in Qatar: a cross-sectional analysis of the Electronic Medical Records for the year 2017. BMJ Open. 2019;9(8):e029334.

14. Nakamura KM, Haglind EG, Clowes JA, Achenbach SJ, Atkinson EJ, Melton LJ 3rd, et al. Fracture risk following bariatric surgery: a population-based study. Osteoporos Int. 2014;25(1):151-8.

15 Yu EW, Lee MP, Landon JE, Lindeman KG, Kim SC. Fracture risk after bariatric surgery: roux-en-y gastric bypass versus adjustable gastric banding. J Bone Miner Res. 2017;32(6):1229-36.

16 Fashandi AZ, Mehaffey JH, Hawkins RB, Schirmer B, Hallowell PT. Bariatric surgery increases the risk of bone fracture. Surg Endosc. 2018;32(6):2650-5.

17 Sukumar D, Schlussel Y, Riedt CS, Gordon C, Stahl T, Shapses SA. Obesity alters cortical and trabecular bone density and geometry in women. Osteoporos Int. 2011;22(2):635-45.

18. Nielson CM, Marshall LM, Adams AL, LeBlanc ES, Cawthon $\mathrm{PM}$, Ensrud K, et al. BMI and fracture risk in older men: the osteoporotic fractures in men study (MrOS). J Bone Miner Res. 2011;26(3):496-502.

19 Premaor MO, Pilbrow L, Tonkin C, Parker RA, Compston J. Obesity and fractures in postmenopausal women. J Bone Miner Res. 2010;25(2):292-7.

Publisher's Note Springer Nature remains neutral with regard to jurisdictional claims in published maps and institutional affiliations.

\section{Authors and Affiliations}

\section{Omar Suhail Alsaed ${ }^{1} \cdot$ Abdul-Wahab Al-Allaf $^{1} \cdot$ Isra Elgenaied $^{2} \cdot$ Rawand Abdelnaser Jebril $^{1} \cdot$ Sreethish Sasi ${ }^{1}$. Ashraf Omer Ahmed ${ }^{1} \cdot$ Rabab Boussarsar $^{2} \cdot$ Mohamed Izham Mohamed Ibrahim $^{3} \cdot$ Ibrahim Abdulmomen $^{1}$. Wahiba Elhag ${ }^{2}$. Samar A. Al Razaq Alemadi ${ }^{1}$}

\author{
Omar Suhail Alsaed \\ oalsaed@hamad.qa \\ Rawand Abdelnaser Jebril \\ Rjebril@hamad.qa \\ Sreethish Sasi \\ ssasi7@hamad.qa \\ Ashraf Omer Ahmed \\ Ashrafzone1@gmail.com \\ Rabab Boussarsar \\ sarro111222@hotmail.com; Rboussarsar@hamad.qa \\ Mohamed Izham Mohamed Ibrahim \\ mohamedizham@qu.edu.qa \\ Ibrahim Abdulmomen \\ Iabdulmomen@hamad.qa
}

Wahiba Elhag

Hibahamid@hotmail.com

Samar A. Al Razaq Alemadi

Salemadi@hamad.qa

1 Department of Medicine, Division of Rheumatology, Hamad Medical Corporation, Doha, Qatar

2 Department of Bariatric and Metabolic Surgery, Hamad Medical Corporation, Doha, Qatar

3 Pharmacy College of Pharmacy, QU Health Qatar University, Doha, Qatar 